\section{MALIGNANCY AFTER HEART TRANSPLANTATION}

Katherine Fan. Cardiac Medicine Unit, Grantham Hospital, Hong Kong SAR

10.1136/heartasia-2019-apahff.25

In the current era, approximately $50 \%$ of heart transplant (HTx) recipients survive more than 13 years, with an increasing population of patients surviving beyond 20 years. Previous studies have suggested that HTx recipients are at particularly high risk of developing de novo malignancies due to more intensive immunosuppression. The perception of higher risk for post-transplant lymphoproliferative disease (PTLD; e.g. lymphoma) associated with OKT3 led to a fall in the use of OKT3 during the 1990s. Main advances in post-HTx management with probable reduction of risk for neoplasia are introduction of (1) antiviral prophylaxis, (2) induction agents that are more specific in their actions and (3) the mammalian target-ofrapamycin inhibitors (mTORs).

Reported incidence of post-transplant malignancy in HTx recipients ranged from $2.3 \%$ to $27 \%$ and skin malignancies represented up to $50 \%$ of post-transplant malignancies. The second most common cancer in HTx recipients was PTLD. A retrospective analysis included 17587 adult $\mathrm{HTx}$ recipients who were followed for up to five years post-operation. ${ }^{1}$ The incidence of de novo malignancy was $10.7 \%$ one to five years after transplantation, with higher prevalence in the contemporary era.

Considering the increased burden of de novo malignancy in HTx recipients, additional effort needs to be directed towards formulating evidence-based cancer screening recommendations and optimised immunosuppression protocols for these patients. It may be reasonable to consider the risk of de novo post transplant malignancy in older patients when making decisions regarding candidacy for HTx versus left ventricular assist device as destination.

\section{REFERENCES}

1. Youn JC, Stehlik J, Wilk AR, Cherikh W, Kim IC, Park GH, Lund LH, Eisen HJ, Kim DY, Lee SK, Choi SW, Han S, Ryu KH, Kang SM, Kobashigawa JA. Temporal trends of de novo malignancy development after heart transplantation. J Am Coll Cardiol 2018;71:40-49.

\section{CARDIOMEMS ${ }^{\mathrm{TM}}$ IN VAD PATIENTS}

Erik Fung. Division of Cardiology, Department of Medicine and Therapeutics, The Chinese University of Hong Kong, Prince of Wales Hospital, Hong Kong SAR

10.1136/heartasia-2019-apahff.26

Successive generations of left ventricular assist devices (LVADs) have been associated with improvement in patient outcomes and reduction in device-related complications. ${ }^{1}$ Beyond mortality reduction, quality of life improvement and reduction in hospitalisation are increasingly focused upon. Following LVAD implantation, the number of admissions per year is highest in the first year. ${ }^{2}{ }^{3}$ In fact, within 30-90 days, hospitalisation for volume overload - indicative of acute worsening heart failure, haemodynamically significant arrhythmias or imbalance of haemodynamics due to suboptimal LVAD pump settings - could account for 11\%-24\% of admissions. $^{2} 45$
To improve our understanding of mechanisms related to VAD therapy, investigators have reviewed data from LVAD patients with pre-operatively placed implantable pulmonary artery pressure (PAP) monitors (CardioMEMS ${ }^{\mathrm{TM}}$ ). Studies have shown that implantation of PAP monitors can assist in management of haemodynamics, thus potentially reducing hospitalisation in a portion of LVAD patients with volume overload. Although retrospective analyses of PAP monitor data suggested that PAP could be effectively reduced by LVAD implantation, ${ }^{6}$ there remains a lack of prospective data to support routine use of PAP monitoring in LVAD patients to guide haemodynamic management. In the ongoing Intellect2, a multi-centre prospective observational 6 month follow-up study of 100 LVAD patients (https://clinicaltrials.gov/ct2/show/NCT03247829), CardioMEMS will be evaluated for its effects on haemodynamics optimisation to impact on patients' functional status, quality of life and hospital medications.

\section{REFERENCES}

1. Mehra MR, Goldstein DJ, Uriel N, Cleveland JC Jr, Yuzefpolskaya M, Salerno C, Walsh MN, Milano CA, Patel CB, Ewald GA, Itoh A, Dean D, Krishnamoorthy A, Cotts WG, Tatooles AJ, Jorde UP, Bruckner BA, Estep JD, Jeevanandam V, Sayer G, Horstmanshof D, Long JW, Gulati S, Skipper ER, O'Connell JB, Heatley G, Sood P, Naka Y; MOMENTUM 3 Investigators. Two-Year Outcomes with a Magnetically Levitated Cardiac Pump in Heart Failure. N Engl J Med 2018:378:1386-1395.

2. Tripathi B, Arora S, Kumar V, Thakur K, Lahewala S, Patel N, Dave M, Shah M, Savani S, Sharma P, Bandyopadhyay D, Shantha GPS, Egbe A, Chatterjee S, Patel NK, Gopalan R, Figueredo VM, Deshmukh A. Hospital complications and causes of 90-Day readmissions after implantation of left ventricular assist devices. Am J Cardiol 2018;122:420-430.

3. Vidula $H$, Kutyifa $V$, Johnson BA, Strawderman RL, Harrington D, Polonsky $B$, Papernov A, Alexis JD. Readmission Patterns During Long-Term Follow-Up After Left ventricular assist device implantation. Am J Cardiol 2018;122:1021-1027.

4. Gupta S, Cogswell RJ, Roy SS, Spratt JR, Liao KK, Martin CM, John R. Impact of 30 Day Readmission After Left Ventricular Assist Device Implantation. ASAIO J 2018 May 7. doi:10.1097/MAT.0000000000000812.

5. Patel S, Poojary P, Pawar S, Saha A, Patel A, Chauhan K, Correa A, Mondal P, Mahajan K, Chan L, Ferrandino R, Mehta D, Agarwal SK, Annapureddy N, Patel J, Saunders P, Crooke G, Shani J, Ahmad T, Desai N, Nadkarni GN, Shetty V. National landscape of unplanned 30-day readmissions in patients with left ventricular assist device implantation. Am J Cardiol 2018;122:261-267.

6. Feldman DS, Moazami N, Adamson PB, Vierecke J, Raval N, Shreenivas S, Cabuay BM, Jimenez J, Abraham WT, O'Connell JB, Naka Y. The utility of a wireless implantable hemodynamic monitoring system in patients requiring mechanical circulatory support. ASAIO J 2018;64:301-308

\section{LOWER LIMB ISCHAEMIA IN PATIENTS UNDERGOING VA ECMO}

Kai Man Chan. Department of Anaesthesia and Intensive Care, Prince of Wales Hospital, Hong Kong SAR

10.1136/heartasia-2019-apahff.27

The incidence of lower limb ischaemia ranges from $11 \%$ $52 \%$ in patients receiving VA ECMO. The reported rate of amputation ranges from $2 \%-10 \%$. Patients with vascular complications related to lower limb ischaemia carries a higher risk of death. Antegrade perfusion of superficial femoral artery via a distal perfusion catheter (DPC) has been shown to be an effective therapy to reduce the incidence of lower limb ischaemia. However, the clinical indications remain largely unclear with various reported strategies. While the benefits remain largely unknown, there is increasing experience on the use of near-infrared reflectance 